\title{
ARAHAN PENATAAN JALUR SIRKULASI GUNA MENUNJANG WALKABILITY PENGUNJUNG PADA TAMAN KOTA DI SURABAYA
}

\author{
Azkia Avenzoar \\ Universitas Pembangunan Nasional "Veteran" Jawa Timur \\ azkiaave.ar@upnjatim.ac.id

\section{Eva Elviana} \\ Universitas Pembangunan Nasional "Veteran" Jawa Timur \\ evaelviana.ar@upnjatim.ac.id \\ Heru Prasetiyo Utomo \\ Universitas Pembangunan Nasional "Veteran" Jawa Timur \\ herupras95.ar@upnjatim.ac.id
}

\begin{abstract}
Abstrak
Taman kota merupakan ruang publik yang senantiasa menarik minat warga kota untuk berkunjung. Kehadiran taman kota ini harus mengindahkan upaya-upaya penataan jalur sirkulasi yang menunjang walkability pengunjung mengingat umumnya taman kota terletak di pusat kota dan dengan rentang usia pengunjung yang tidak terbatas. Oleh karena itu, penataan jalur sirkulasi dengan penekanan walkability perlu diperhatikan. Objek studi adalah taman kota di Surabaya yang terletak di pulau jalan dan dikelilingi oleh jalan arteri. Metode pengumpulan data menggunakan walkthrough analysis yang hasilnya dituangkan dalam foto dan sketsa. Variabel yang digunakan adalah 5C's walkability audit yakni connected, comfortable, convenient, convivial, dan conspicuous. Hasilnya adalah arahan penataan jalur sirkulasi berupa jalur penyeberangan yang sebidang dan dilengkapi pengamanan yang sesuai, peletakan jalur penyeberangan di setiap sisi taman, jalur masuk taman yang berdekatan dengan jalur penyeberangan, dan pemanfaatan taman sebagai pusat informasi kota.
\end{abstract}

Kata-kata Kunci: Taman Kota, Ruang Publik, Jalur Sirkulasi, Walkability

\section{PLANNING DIRECTION OF CIRCULATION PATH TO SUPPORT VISITORS WALKABILITY IN CITY GARDEN IN SURABAYA}

\begin{abstract}
City-parks are public spaces that always attract to be visited. City-park has to the concern of the circulation path to support the visitor's accessibility. Most parks are located in the center of the city and visited by various age of visitors. Therefore, the arrangement of the circulation path that is concerned with walkability has to be considered. The study object is a city park in Surabaya, which is located on a road island and is surrounded by arterial roads. The data collection method is a walk-through analysis completed with photos and sketches. This research uses 5C's walkability audit
\end{abstract}


as variables: connected, comfortable, convenient, convivial, and conspicuous. The result is a direction for arrangement circulation path; there are crosswalks in the same level area and combined with appropriate street furniture, crosswalks on each side of the park, park entrance adjacent with crosswalks, and city-park as central information of the city.

Keywords: City-Park, Public Space, Circulation Path, Walkability

\section{Pendahuluan}

Pertumbuhan masyarakat yang tinggal di wilayah perkotaan dari tahun ke tahun mengalami kenaikan yang cukup signifikan. Pada tahun 1990, jumlah penduduk perkotaan adalah 55,4 juta jiwa yang merupakan 30,9\% dari jumlah total penduduk nasional. Kemudian tahun 2002 meningkat menjadi 90 juta jiwa atau $44 \%$ dari jumlah penduduk nasional. Kemudian secara berurutan pada tahun 2010 menjadi 49,8\% dan tahun 2020 menjadi 56,7\% (Data BPS, 2020). Singkatnya adalah saat ini sudah separuh lebih penduduk Indonesia hidup di wilayah perkotaan. Kenyataan bahwa kenaikan jumlah penduduk kota ini tidak bisa diikuti oleh bertambah luasnya lahan kota harus disiasati oleh penataan ruang kota yang baik, khususnya pada ketersediaan dan penataan kawasan hunian, fasilitas umum dan sosial, serta ruang terbuka publik.

Ruang terbuka publik dalam tata ruang kota ibarat pembuluh darah dalam tubuh (Ramayana, 2017). Apabila ada hambatan dalam aliran darah ini maka tubuh akan mengalami gejala sakit dan apabila dibiarkan akan menjadi penyakit yang membahayakan jiwa, yakni kota itu sendiri. Untuk itu, pada konsep pembangunan kota secara berkelanjutan (Sustainable City Development), keberadaan ruang terbuka publik diharapkan mampu mewujudkan kehidupan yang seimbang, baik dari segi fisik, ekologi, maupun sosial.

Kota Surabaya mengalami pertumbuhan dan perkembangan yang tidak dapat dihindari. Semakin maraknya pembangunan dan penggunaan kendaraan bermotor dapat memicu penurunan kualitas lingkungan yang harus segera diatasi dan dikendalikan. Oleh karena itu, upaya-upaya untuk optimalisasi ruang terbuka hijau sebagai ruang publik perlu ditingkatkan, baik dari sisi pengelolaan, maupun dari sisi fisik RTH itu sendiri (RPJMD Kota Surabaya tahun 2016-2021).

Sepuluh tahun terakhir, Kota Surabaya memiliki kemajuan pesat dalam hal pembangunan taman-taman kota. Lahan-lahan aset Pemerintah Kota yang kurang produktif dimanfaatkan untuk pembangunan taman. Selain sebagai peningkatan kualitas lingkungan, taman kota tersebut juga sebagai sarana untuk memperindah wajah kota. Definisi taman kota sebagaimana tercantum dalam Permen PU No. 05 Tahun 2008 disebutkan bahwa taman kota merupakan lahan terbuka yang berfungsi secara sosial dan estetik sebagai sarana kegiatan rekreatif, edukasi, atau kegiatan lain pada tingkat kota. Taman kota bertujuan untuk melayani penduduk satu kota atau bagian wilayah kota. Peningkatan fungi taman kota sebagai RTH salah satunya perlu didukung oleh kemudahan akses bagi warga untuk mengunjungi taman kota tersebut.

Pada tataran diskusi mengenai ruang kota, keberadaan ruang terbuka publik harus senantiasa menjadi daya tarik bagi warga kota. Ruang terbuka publik bagaikan oase dalam himpitan ruang kota yang semakin hari semakin sesak. Sehingga sebagai bagaian dari ruang kota, ruang terbuka publik hendaknya direncanakan untuk dapat responsif, dapat diakses oleh segala macam usia dan gender (demokratis) serta memiliki arti (Carr, 1992). Untuk itu penelitian ini berusaha untuk memberi kontribusi berupa optimalisasi pengelolaan RTH melalui penataan jalur sirkulasi guna menunjang walkability pengunjung pada taman kota sebagai bagian dari sub-sistem ruang terbuka hijau.

Pada klasifikasi ruang kota, taman kota berada dalam sub-klasifikasi dari ruang terbuka (open space). Ruang Terbuka (open space) merupakan suatu wadah yang menampung aktivitas manusia dalam suatu lingkungan yang tidak mempunyai penutup dalam bentuk fisik (Budihardjo, 1999). Ruang Terbuka ini terbagi menjadi ruang terbuka tanpa penghijauan, dan ruang terbuka dengan 
penghijauan. Zahnd (2006) menyebutkan bahwa open space yang perlu dibahas secara objektif dan umum dengan memperhatikan tiga prinsip yakni (1) Open space adalah ruang terbuka yang lebih berarti daripada sesuatu yang kosong saja; (2) Dibentuk secara organis atau teknis oleh benda-benda yang membatasinya; (3) Open space terbagi atas tiga aspek yang fungsional

Pada data integrasi RPJMD (Rencana Pembangunan Jangka Menengah Daerah) 2016-2021 terhadap RTRW (Rencana Tata Ruang dan Wilayah) 2014-2034 Kota Surabaya disebutkan bahwa program pengelolaan dan peningkatan Ruang Terbuka Hijau antara lain (1) Melindungi dan tidak mengalihfungsikan ruang terbuka hijau; (2) Mengembangkan kegiatan olahraga dan pariwisata pada fungsi-fungsi ruang terbuka hijau tertentu; (3) Meningkatkan fungsi ekologis pada setiap fungsi ruang terbuka hijau; (4) Menata dan mengatur setiap fungsi ruang terbuka hijau (Sumber: RPJMD Kota Surabaya 2016-2021).

Tabel 1. Luas RTH Publik Kota Surabaya Tahun 2015

\begin{tabular}{clr}
\hline No. & \multicolumn{1}{c}{ JENIS RTH PUBLIK } & LUAS (Ha) \\
1. & RTH makam & 281,55 \\
\hline 2. & RTH lapangan & 346,55 \\
\hline 3. & RTH telaga/waduk/ boezem & 176,42 \\
\hline 4. & RTH dari fasum dan fasos permukiman & 160,43 \\
\hline 5. & RTH kawasan lindung & $4.198,54$ \\
\hline 6. & RTH hutan & 41,89 \\
\hline 7. & RTH taman dan jalur hijau (JH) & $1.647,71$ \\
\hline Jumlah Luasan RTH Publik & $6.853,09$ \\
\hline Luas Kota Surabaya & 33,048 \\
\hline Prosentase luas RTH thd. luas kota & $\mathbf{2 0 , 7 4 \%}$ \\
\hline
\end{tabular}

Sumber: RPJMD Kota Surabaya 2016-2021

Jika merujuk pada Permen PU No. 5 Tahun 2008 yang menyatakan bahwa proporsi Ruang Terbuka Hijau (RTH) di kawasan perkotaan adalah 30\% dari luas kota yang terdiri dari 20\% RTH publik dan $10 \%$ RTH privat, maka Kota Surabaya telah memiliki prosentase RTH publik yang sudah sesuai. Sehingga poin penting pada tata kelola RTH selanjutnya adalah melindungi, menata, dan meningkatkan fungsi-fungsi RTH. Kemudian jika data tersebut ditinjau lebih dalam lagi, maka dapat diketahui bahwa RTH taman dan jalur hijau memberikan kontribusi luas terbesar kedua setelah RTH kawasan lindung. Hal ini menegaskan bahwa posisi taman kota sebagai sub-struktur dari ruang terbuka hijau memiliki peran penting pada ketersediaan RTH publik. Oleh karena itu, perlu adanya arahan dan standar perencanaan taman kota yang matang.

Taman kota adalah salah satu ruang publik kota yang dinikmati dengan aktivitas berjalan. Untuk itu perlu dukungan konsep walkability, baik dari eksternal maupun internal taman. Walkability adalah istilah yang digunakan untuk menggambarkan konektivitas dan kualitas jalan setapak atau trotoar (Leather et al., 2011). Konsep walkability tidak hanya berupa penyediaan trotoar saja, melainkan juga hal-hal terkait di dalamnya seperti konektivitas trotoar, kualitas perkerasan, kemiringan tanjakan, dan estetika (The Genesee Transportation Council, 2016).

Pada studi yang dilakukan oleh Transport for London tentang Improving Walkability (2005), terdapat variabel yang digunakan untuk menilai walkability, yaitu: (1) Konektifitas (Connected); (2) Kenyamanan (Comfortable); (3) Kesesuaian (Convenient); (4) Keramahan (Convivial); (5) Kejelasan (Conspicuous). Penjabaran dan fitur-fitur terkait penilaian walkability ini dipaparkan oleh Asin, n.d.(2008), Herbes, (2010) Grant (2010) dan Moura (2017) antara lain: (1) Connected: Keterhubungan taman kota terhadap ruang-ruang kota lainnya, termasuk transportasi publik dan halte-halte pemberhentiannya; (2) Comfortable: Ukuran jalur pedestrian dan permukaan yang nyaman, dan akses untuk penyandang cacat, serta memiliki pepohonan dengan peneduhan yang cukup; (3) Convenient: Penempatan penyeberangan jalan dan street furniture yang sudah sesuai; (4) 
Convival: Bebas dari gangguan, misalnya ranting pohon, pot tanaman, furnitur jalan; (5) Conspicuous: Rute jalur pedestrian sudah cukup jelas, dan apakah penanda dan rambu-rambu jalan bekerja dengan baik.

Pada studi lain yang sejenis, Institute for Transportation and Development Policy mengeluarkan publikasi tentang studi walkability pada skala kota (www.itdp.org, 2018). Studi ini memaparkan tentang penilaian walkable city berdasarkan hirarki dan tingkat ketercapaian walkability-nya. Mulai dari paling rendah yaitu (1) Passable; (2) Accessible; (3) Safe; (4) Convenient; (5) Comfortable; dan (6) Enjoyable. Berikut adalah diagram hirarki walkable city yang dipaparkan pada studi tersebut:
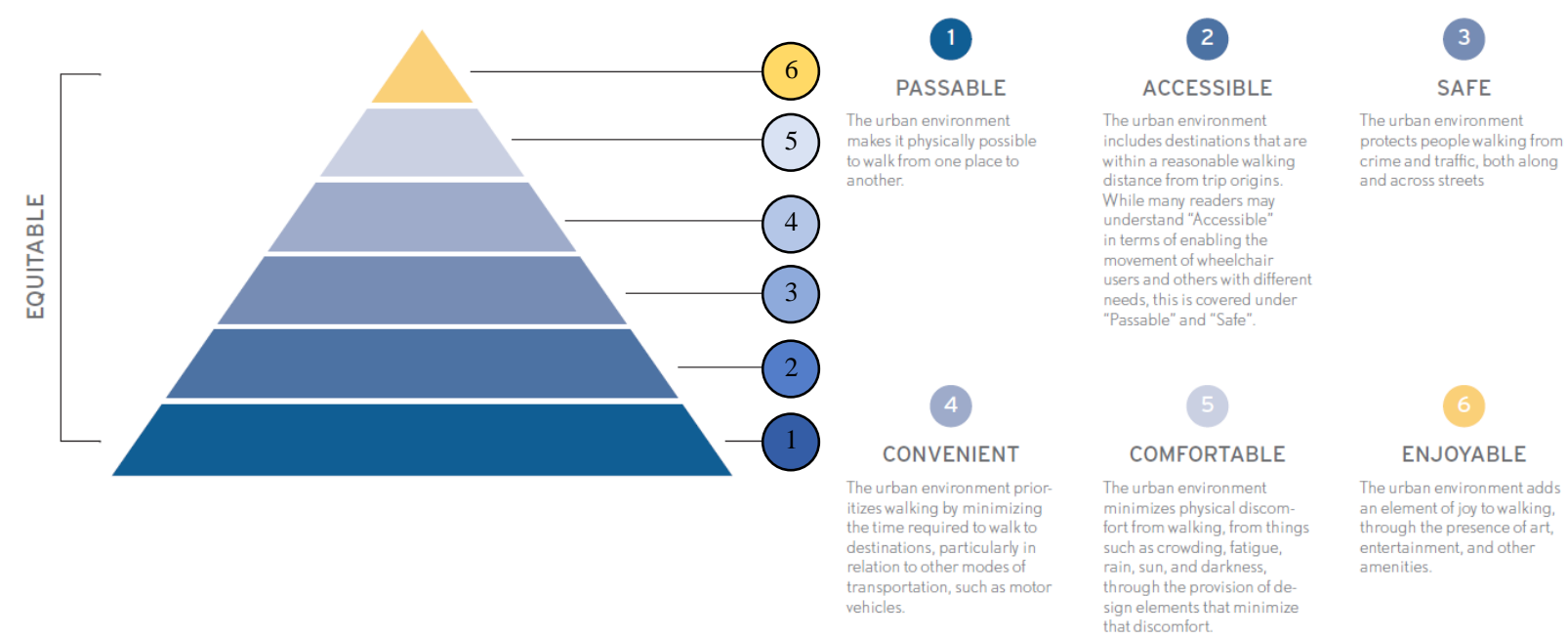

Gambar 1. Piramida Hirarki Ketercapaian Walkability Sumber: Institute for Transportation and Development Policy, 2018

Pada tataran arahan regulasi, Permen PU Nomor 03 tahun 2014 memberikan Pedoman Perencanaan, Penyediaan, dan Pemanfaatan Prasarana dan Sarana Jaringan Pejalan Kaki di Kawasan Perkotaan. Pada pedoman tersebut terdapat arahan mengenai aksesibilitas bagi pejalan kaki, antara lain (1) Harus dapat diakses oleh semua pejalan kaki termasuk bagi yang memiliki keterbatasan fisik; (2) Pemilihan jenis tanaman yang dapat melingkupi dan memberikan penunjuk arah; (3) Perabot ruang yang sesuai dan mudah dijangkau; (4) Terdapat papan informasi dan rambu-rambu yang dapat terlihat dengan mudah; (5) Terdapat ramp dan marka bagi penyandang disabilitas dan dapat digunakan sebagaimana mestinya.

Berdasarkan paparan mengenai teori ruang taman kota, variabel walkability, serta pedoman mengenai sarana pejalan kaki di atas, maka ditetapkanlah variabel pengamatan dan indikator penelitian sebagai berikut:

Tabel 2. Variabel Dan Indikator Penelitian

\begin{tabular}{ll}
\hline \multicolumn{1}{c}{ Variabel } & \multicolumn{1}{c}{ Indikator } \\
\hline $\begin{array}{ll}\text { Konektifitas (Connected) } \\
\text { adalah mengenai bagaimana }\end{array}$ & - Lingkungan yang bisa dilalui secara fisik (passable \& accessible) \\
keterhubungan taman kota & - Memiliki jalur pedestrian, jalur penyeberangan dan akses masuk \\
terhadap ruang-ruang kota lainnya, & ke dalam taman dapat diakses oleh semua pejalan kaki termasuk \\
termasuk transportasi publik dan & bagi yang memiliki keterbatasan fisik; \\
halte-halte pemberhentiannya; & - Taman kota dilalui oleh transportasi publik; \\
\hline $\begin{array}{l}\text { Kenyamanan (Comfortable) } \\
\text { adalah mengenai standar ukuran }\end{array}$ & - Jalur pedestrian memiliki ukuran yang cukup lebar yakni 1,8-3 \\
jalur pedestrian yang nyaman, & meter (accessible); \\
\hline
\end{tabular}




\begin{tabular}{|c|c|}
\hline $\begin{array}{l}\text { finishing permukaannya, dan akses } \\
\text { untuk penyandang cacat, serta } \\
\text { memiliki pepohonan dengan } \\
\text { peneduhan yang cukup; }\end{array}$ & $\begin{array}{l}\text { sehingga tidak licin (safe); } \\
\text { - Jalur pedestrian memiliki pepohonan dengan peneduhan yang } \\
\text { cukup (enjoyable); }\end{array}$ \\
\hline $\begin{array}{l}\text { Kesesuaian (Convenient) } \\
\text { adalah mengenai apakah } \\
\text { penempatan penyeberangan dan } \\
\text { furnitur jalan lainnya sudah sesuai; }\end{array}$ & $\begin{array}{l}\text { - Penempatan jalur penyeberangan (zebra-cross) yang sesuai dan } \\
\text { memadai; } \\
\text { - Penempatan street-furniture yang sesuai. }\end{array}$ \\
\hline $\begin{array}{l}\text { Keramahan (Convivial) } \\
\text { adalah mengenai apakah jalur } \\
\text { pedestrian bebas dari gangguan, } \\
\text { misalnya ranting pohon, pot } \\
\text { tanaman, furniture jalan, dan lain } \\
\text { sebagainya; }\end{array}$ & $\begin{array}{l}\text { - Jalur pedestrian bebas dari hambatan berupa pot, ranting pohon, } \\
\text { dan sejenisnya (passable); } \\
\text { - Taman kota telah dilengkapi dengan street-furniture yang } \\
\text { memadai, yaitu tempat duduk, tempat sampah, lampu taman, } \\
\text { bollard, dan sejenisnya }\end{array}$ \\
\hline $\begin{array}{l}\text { Kejelasan (Conspicuous) } \\
\text { adalah mengenai apakah rute jalur } \\
\text { pedestrian sudah cukup jelas, dan } \\
\text { apakah penanda dan rambu-rambu } \\
\text { jalan bekerja dengan baik. }\end{array}$ & $\begin{array}{l}\text { - Taman kota memiliki identitas atau nama yang jelas; } \\
\text { - Memiliki papan informasi dan rambu-rambu yang bekerja sesuai } \\
\text { dengan fungsinya. }\end{array}$ \\
\hline
\end{tabular}

Sumber: Analisa Penulis, 2020

\section{Metode}

Jenis penelitian yang dilakukan adalah berupa penelitian kualitatif, dengan metode pemaparan secara deskriptif. Cara untuk memperoleh data pada penelitian kualitatif ini tidak mengandalkan pengukuran melainkan menggunakan data sekunder dan fakta berupa pengamatan langsung (observasi) yang dijabarkan secara deskriptif (Darjosanjoto, 2006) untuk kemudian dianalisis dengan variabel kualitatif yang sudah disusun sebelumnya.

Pengumpulan data dan fakta dilakukan dengan metode walk-through analysis yang dikutip dari buku Urban Design Toolkit (Rice, 2008) yaitu dengan berjalan melalui suatu area. Teknik analisa ini digunakan untuk menghasilkan gambaran tentang masalah kualitas perkotaan baik itu yang berhasil maupun yang gagal. Hasil dari teknik ini kemudian direkam dan disajikan secara grafis, yaitu melalui foto dan sketsa. Variabel penilaian yang digunakan adalah $5 C$ 's walkability audit berdasarkan studi yang dilakukan oleh Transport for London tentang Improving Walkability (2005).

\section{Hasil dan Pembahasan}

Menurut data dari Dinas Kebersihan dan Ruang Terbuka Hijau (DKRTH) Kota Surabaya disebutkan bahwa saat ini terdapat 25 titik taman kota. Taman-taman ini tersebar di seluruh wilayah Kota Surabaya dengan karakternya masing-masing. Misalnya, taman-taman monumen dengan karakter formal seperti Taman Tugu Pahlawan, dan Taman Apsari di depan Gedung Grahadi Surabaya.

Taman-taman kota di Surabaya memiliki tema-tema tertentu yang diangkat untuk memperkuat citra kawasan atau tema apapun yang ada kaitannya dengan Kota Surabaya. Taman Sejarah (dulu Taman Jayengrono) dibuat dan diberi nama demikian karena terletak dengan Jembatan Merah yang menjadi salah satu titik tempur perjuangan para pahlawan dalam mempertahankan kemerdekaan. Kemudian Taman Prestasi yang diberi nama demikian karena menjadi tempat untuk menunjukkan prestasi-prestasi Kota Surabaya baik di bidang lingkungan hidup maupun prestasi lainnya. Berikut ini adalah peta persebaran taman kota di Surabaya: 


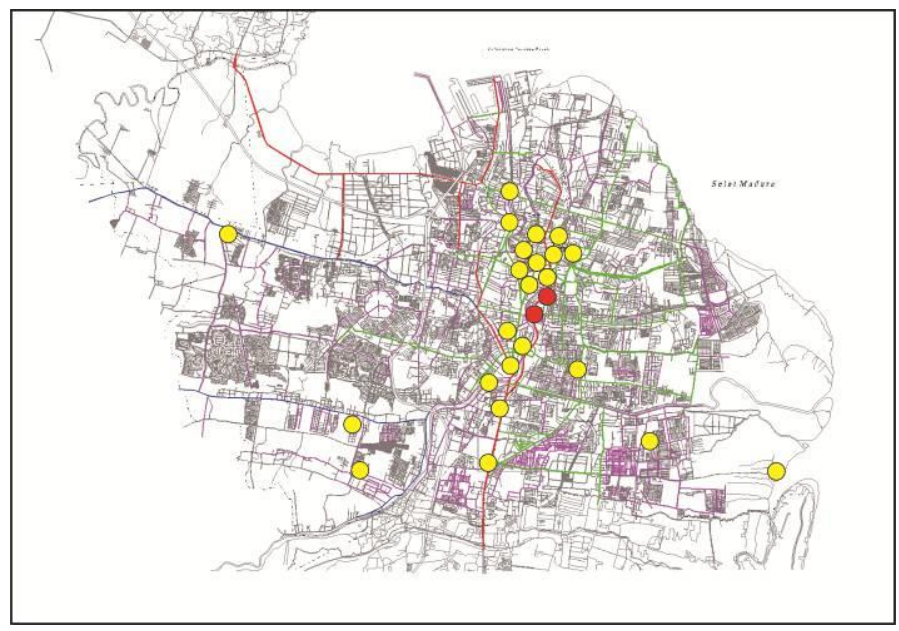

Gambar 2. Persebaran Taman Kota di Surabaya (Titik merah: Obyek Studi)

Sumber: Dokumentasi Pribadi, 2020

Pola persebaran taman kota di Surabaya sebagaimana terlihat pada Gambar 1 di atas menunjukkan bahwa mayoritas taman terletak di pusat kota. Hal ini menegaskan bahwa peningkatan penyediaan taman skala kota yang merata memang sangat dibutuhkan sebagaimana disebutkan dalam RPJMD Kota Surabaya 2016-2021. Berikut adalah data taman kota di Surabaya berdasarkan lokasi, luas dan karakternya:

Tabel 3. Data Taman Kota di Surabaya

\begin{tabular}{cllrl}
\hline No & \multicolumn{1}{c}{ Nama Taman } & \multicolumn{1}{c}{ Lokasi } & Luas $\left(\mathrm{m}^{2}\right)$ & Karakter \\
\hline 1 & Tmn. Prestasi & J1. Ketabangkali & 6000 & Aktif \\
\hline 2 & Tmn. Ekspresi & J1. Gentengkali & 6019 & Aktif \\
\hline 3 & Tmn. Buah & J1. Undaan Kulon & 1255 & Aktif \\
\hline 4 & Tmn. Mundu & J1. Tambaksari & 6500 & Aktif \\
\hline 5 & Tmn. Teratai & J1. Teratai & 4066 & Aktif \\
\hline 6 & Tmn. Paliatif & J1. Soka & 1240 & Aktif \\
\hline 7 & Tmn. Bungkul & J1. Raya Darmo & 9000 & Aktif \\
\hline 8 & Tmn. Mayangkara & J1. A. Yani & 7440 & Aktif \\
\hline 9 & Tmn. Bahari & J1. Raya Darmo & 1935 & Pasif \\
\hline 10 & Tmn. Pelangi & J1. A. Yani & 5557 & Aktif \\
\hline 11 & Tmn. Ronggolawe & J1. Gunungsari & 3940 & Aktif \\
\hline 12 & Tmn. Lansia & J1. Kalimantan & 2000 & Aktif \\
\hline 13 & Tmn. Persahabatan & J1. Sulawesi & 2259 & Aktif \\
\hline 14 & Tmn. Lesti & J1. Lesti & 2214 & Aktif \\
\hline 15 & Tmn. Bangkingan & J1. Bangkingan & 171,42 & Aktif \\
\hline 16 & Tmn. Kunang- & J1. Penjaringansari & 8300 & Aktif \\
\hline 17 & Tmn. Sejarah & J1. Rajawali & 5231 & Aktif \\
\hline 18 & Tmn. Skate \& BMX & J1. Ketabangkali & 4500 & Aktif \\
\hline 19 & Tmn. Surya & J1. W. Mustajab & 12.600 & Aktif \\
\hline 20 & Tmn. Apsari & J1. Pemuda & 5300 & Aktif \\
\hline 21 & Tugu Pahlawan & J1. Pahlawan & 13.370 & Aktif \\
\hline 22 & Tmn. Korea & J1. Dr. Soetomo & 2600 & Aktif \\
\hline 23 & Tmn. Flora & J1. Manyar & 33.810 & Aktif \\
\hline 24 & Tmn. Mozaik & J1. Wiyung Praja & 5.100 & Aktif \\
\hline 25 & Tmn. Suroboyo & J1. Pantai Kenjeran & 11.900 & Aktif \\
\hline & & & \\
\hline
\end{tabular}

Sumber: DKRTH Kota Surabaya, 2020

Objek studi pada penelitian ini terletak di pusat kota, yakni Taman Lansia yang terletak di Jalan Raya Gubeng dan Taman Persahabatan yang terletak di Jalan Sulawesi. Alasan pemilihan objek adalah lokasinya di pusat kota dan terletak di pulau jalan yang dikelilingi oleh penggal jalan arteri. Ruang di pulau jalan dan dikelilingi oleh jalan arteri memiliki karakteristik tersendiri terkait 
penyesuaian terhadap lalu lintas. Berikut ini adalah hasil observasi dan analisa walk-through atas objek studi:

\section{Taman Lansia}

Taman ini dibatasi oleh tiga penggal jalan yang berbeda, yaitu Jalan Raya Gubeng dengan fungsi arteri primer, Jalan Biliton dengan fungsi arteri sekunder, dan Jalan Kalimantan dengan fungsi jalan lokal. Jalan Raya Gubeng dan Jalan Biliton merupakan jalan satu arah dengan masing-masing empat dan dua lajur, sedangkan Jalan Kalimantan merupakan jalan satu arah dengan dua lajur. Sisi taman yang berbatasan dengan Jalan Raya Gubeng terdapat rambu larangan parkir, sedangkan pada sisi Jalan Biliton terdapat rambu larangan berhenti. Dengan demikian parkir kendaraan pengunjung diletakkan di Jalan Kalimantan dengan sistem on street parking. Taman ini memiliki bentuk geometri segitiga yang dikelilingi oleh ruko, perkantoran dan area komersial lainnya. Kawasan permukiman terletak agak jauh dari taman ini.

Nama dan tema Taman Lansia ini diambil dari keberadaan fasilitas jalur refleksi kaki yang dapat dimanfaatkan oleh para lansia (lanjut usia). Selain itu, semua jalur-jalur sirkulasi yang ada merupakan ramp tanpa anak tangga sehingga memudahkan jalannya kursi roda. Dua fasilitas ini diarahkan untuk dimanfaatkan oleh kalangan lansia. Jalan di sekitar taman ini dikelilingi oleh angkutan umum, baik bis kota maupun lyn, diantaranya adalah lyn G, lyn GS, lyn N, lyn RT, lyn T2, lyn UBB, dan lyn $\mathrm{W}$ sehingga dapat menghubungkan taman dengan bagian kota lainnya.
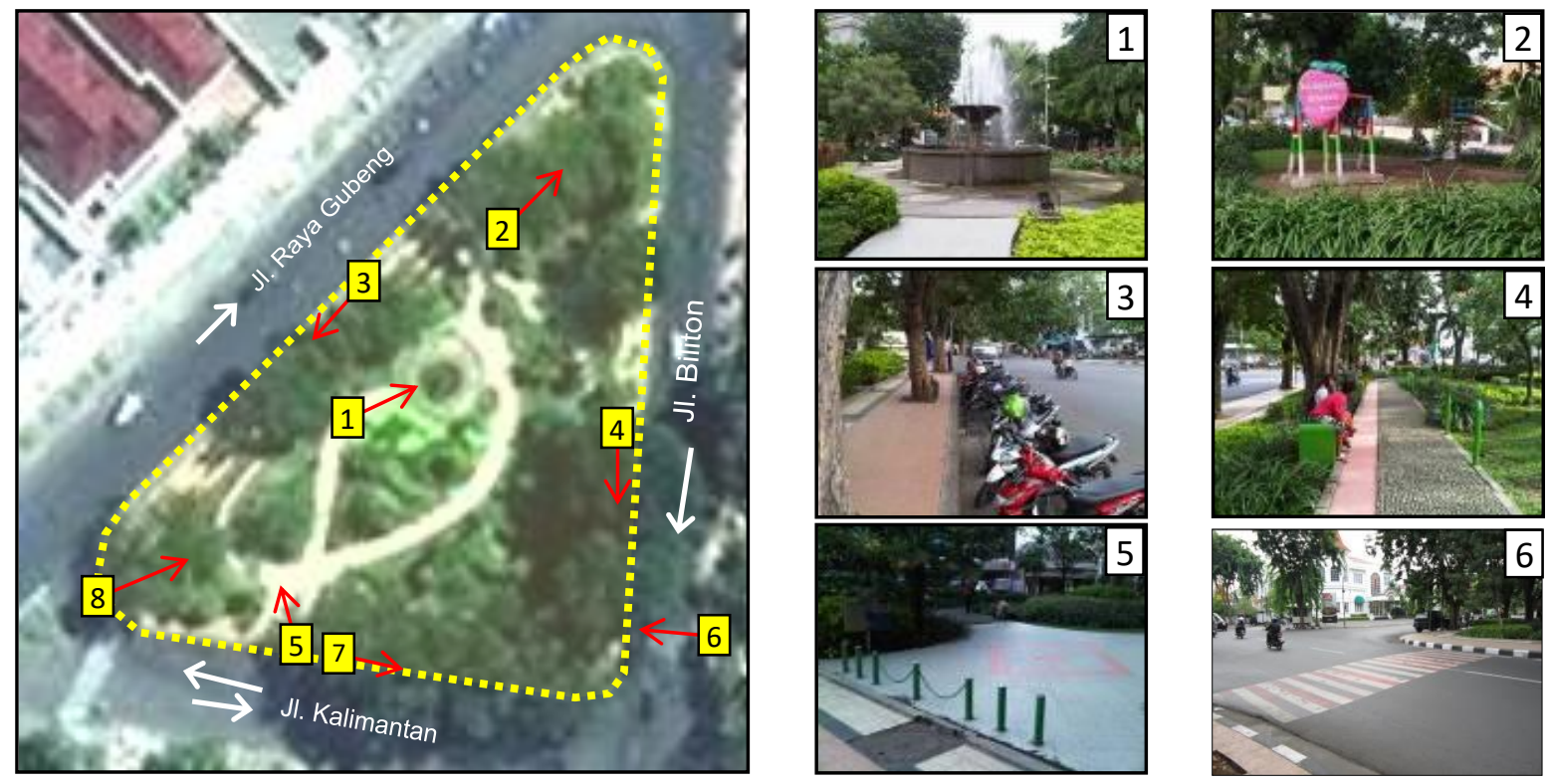

1. Air mancur

2. Area playground

3. Area parkir motor (on-street parking)

4. Jalur pijat refleksi kaki

5. Entrance taman

6. Jalur penyeberangan yang tidak sejajar jalur pedestrian

Gambar 3. Taman Lansia

Sumber: Dokumentasi Pribadi, 2019

Taman ini telah dikelilingi oleh trotoar selebar 2-3 meter dan memiliki naungan pohon di trotoarnya (lihat foto $3,4,7$, dan 8), sehingga cukup nyaman untuk pejalan kaki maupun penyandang cacat. Taman ini memiliki titik penyeberangan jalan di ketiga sisinya, sehingga konektifitas dengan 
lingkungan sekitarnya tetap terjaga. Namun ada satu titik penyeberangan (lihat foto 6) yang kurang memperhatikan kenyamanan pengunjung, yakni jalur penyeberangan yang tidak sebidang sehingga agak menyulitkan para penyandang disabilitas. Arahan yang bisa diterapkan adalah dengan mengangkat bidang jalan kendaraan agar sejajar jalur pedestrian atau agak menurunkan jalur pedestrian agar sejajar jalan dengan penambahan bollard sebagai pengaman. Berikut ini adalah ilustrasi arahan yang dapat diaplikasikan:

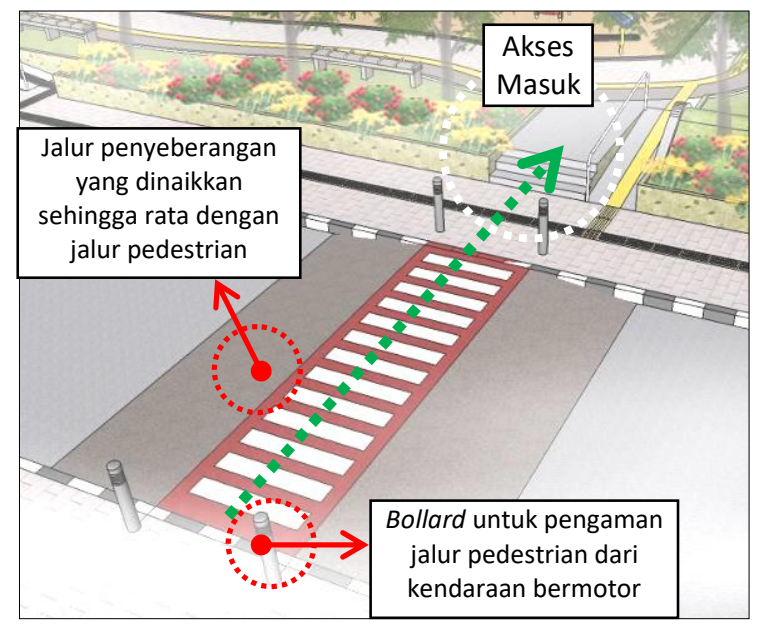

Gambar 4. Jalur penyeberangan sebidang Sumber: Dokumentasi Pribadi, 2020

Taman Lansia sudah dilengkapi dengan jalur penyeberangan di sekeliling taman dan ramburambu pelengkap di sekelilingnya. Berikut ini adalah gambaran atas hasil observasi lapangan yang disajikan dalam bentuk grafis dan tabel untuk menunjukkan posisi jalur penyeberangan, akses dan jenis masuk taman, rambu-rambu yang digunakan, dan sebagainya.

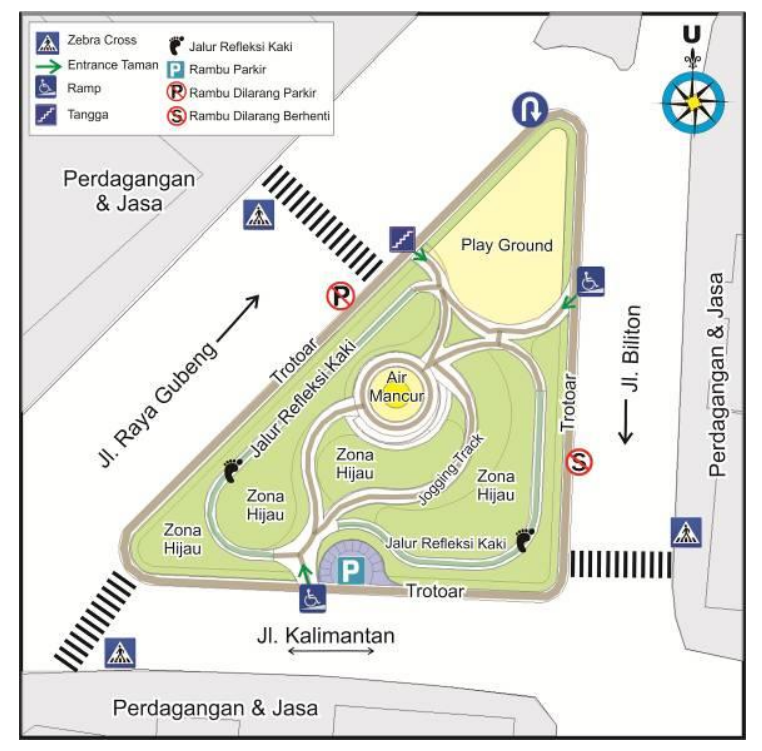

Gambar 5. Infografis Taman Lansia Sumber: Dokumentasi Pribadi, 2020 
Tabel 4. Hasil Analisa Walk-Through Taman Lansia

\begin{tabular}{l} 
Indikator; Hasil Analisa Walk-through \\
\hline Var.
\end{tabular}

Sumber: Analisa Penulis, 2020

\section{Taman Persahabatan}

Taman Persahabatan ini berbentuk segiempat (jajaran genjang) yang dibatasi oleh empat koridor jalan, antara lain Jalan Kertajaya, Jalan Raya Gubeng, Jalan Sulawesi, dan Jalan Sumatra. Jalan Kertajaya merupakan jalan arteri sekunder, dan Jalan Raya Gubeng merupakan jalan arteri primer. Jalan Kertajaya memiliki empat lajur kendaraan satu arah. Kemudian Jalan Raya Gubeng juga memiliki empat lajur yang dibagi dalam dua arah. Jalan Sulawesi dan Jalan Sumatra yang masing-masing memiliki dua lajur searah. Taman ini dikelilingi oleh area dengan fungsi perkantoran, perdagangan dan jasa, serta permukiman.

Taman ini berdiri di atas lahan bekas SPBU (Stasiun Pengisian Bahan bakar Umum) yang sudah pindah di seberangnya. Area parkir diletakkan di dalam site sehingga tidak mengganggu jalan. Nama taman ini diambil dari prasasti-prasasti persahabatan antar kota yang ditandatangani Walikota Surabaya dengan walikota kota-kota sahabat. Terdapat 6 prasasti yang ditandatangani dengan Walikota Surabaya, antara lain dengan Kota Yogjakarta, Kota Batam, Kota Kochi (Jepang), Kota Bandung, Kota Banjarmasin, Kabupaten Sidoarjo. 

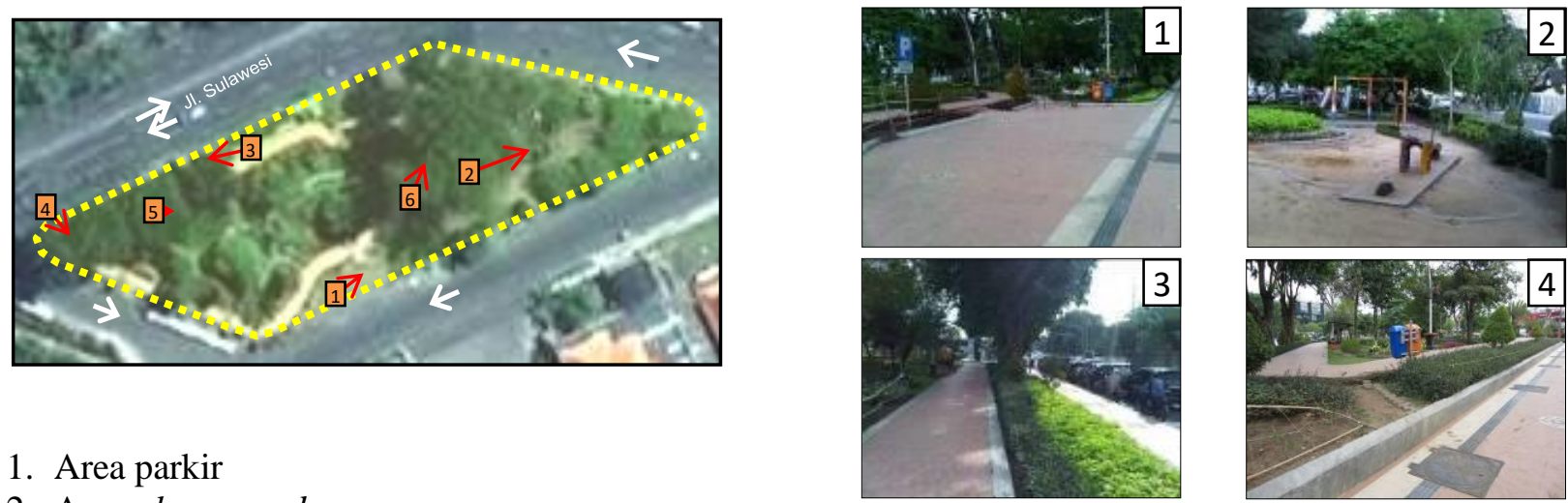

1. Area parkir

2. Area playground

3. Sirkulasi internal \& eksternal

4. Akses masuk ilegal

5. Prasasti persahabatan kota

6. Tempat duduk/seating
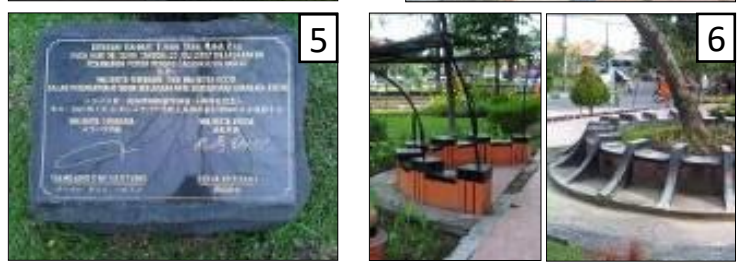

Gambar 6. Taman Persahabatan

Sumber: Dokumentasi Pribadi, 2019

Taman ini dilalui oleh bis kota maupun lyn, antara lain lyn G, lyn GS, lyn N, lyn RT, lyn T2, lyn UBB, dan lyn W sehingga angkutan umum ini dapat menghubungkan taman dengan bagian kota lainnya. Jalur pedestrian di sekeliling taman ini sudah tersedia dengan lebar 1,5-2 meter berbahan keramik kasar. Kemudian di sebelah barat taman terdapat jalur penyeberangan yang menyatu dengan lampu lalu lintas (traffic light). Namun di sisi taman yang lain tidak dilengkapi dengan jalur penyeberangan, sehingga keterhubungan dengan lingkungan sekitar rendah (lihat Gambar 6). Untuk itu arahan penelitian ini adalah melengkapi sisi tersebut dengan jalur penyeberangan.

Temuan lain yang didapatkan dari hasil observasi taman ini adalah adanya jalur masuk ke dalam taman yang tidak sesuai dengan peruntukannya (lihat Gambar 3, Foto no. 4). Jalur masuk ilegal ini terbentuk akibat pengunjung yang ingin segera masuk ke dalam taman setelah menyeberang. Hal ini juga terjadi di Taman Lansia. Oleh karena itu, arahan yang dapat diaplikasikan adalah dengan memberikan jalur masuk ke dalam taman yang berdekatan dengan jalur penyeberangan. Berikut ini adalah ilustrasi arahan yang dapat diaplikasikan:

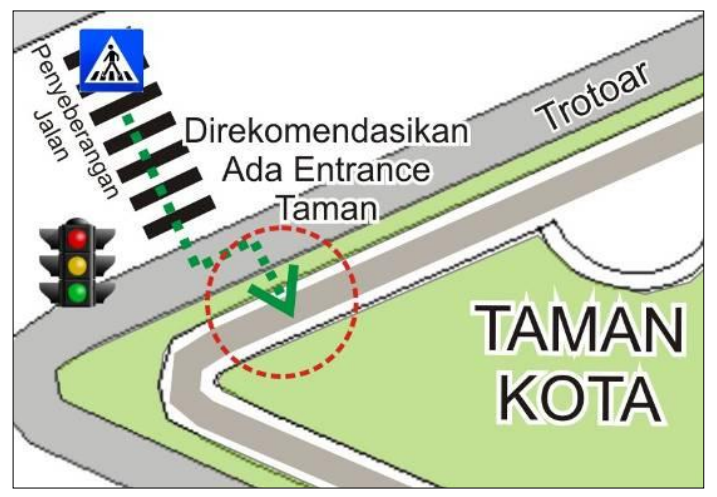

Gambar 7. Jalur Masuk Taman Yang Diletakkan Berdekatan Dengan Jalur Penyeberangan Sumber: Dokumentasi Pribadi, 2020 
Taman Persahabatan belum dilengkapi dengan jalur penyeberangan di setiap sisi taman, namun sudah dilengkapi dengan rambu-rambu pengaman di sekelilingnya. Berikut ini adalah gambaran atas hasil observasi lapangan yang disajikan dalam bentuk grafis dan tabel untuk menunjukkan posisi jalur penyeberangan, jalur dan jenis masuk taman, rambu-rambu yang digunakan, dan sebagainya.

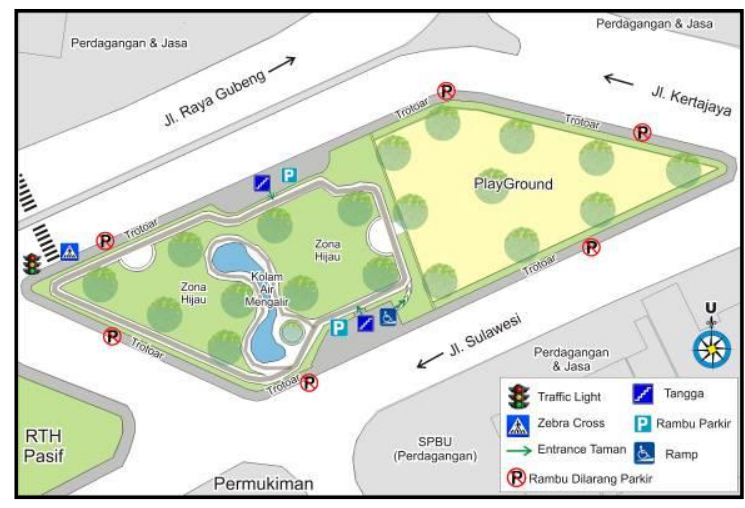

Gambar 8. Infografis Taman Persahabatan Sumber: Dokumentasi Pribadi, 2020

Tabel 5. Hasil Analisa Walk-Through Taman Persahabatan

Var. Indikator; Hasil Analisa Walk-through

- Jalur penyeberangan terletak hanya di dua sisi taman, dan tidak tersedia di sisi selatan ataupun timur. Hal ini mengurangi keterhubungan ruang taman dengan lingkungan sekitar. Pengunjung dari sisi

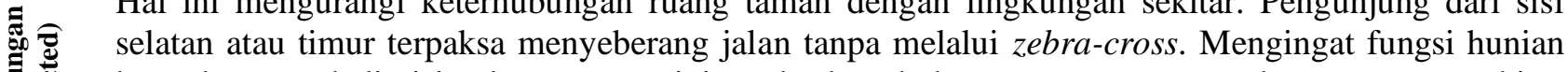
banyak muncul di sisi selatan taman ini, maka keterhubungan ruang taman dengan warga sekitar taman menjadi rendah.

- Jalur penyeberangan yang ada belum memiliki permukaan yang sebidang sehingga aksesibilitas bagi penyandang cacat menjadi berkurang.

- Taman ini dilintasi oleh transportasi publik, namun belum dilengkapi dengan halte pemberhentian.

- Jalur pedestrian berukuran lebar 1,5-2 meter sehingga sudah nyaman bagi pejalan kaki yang berjalan

₹ maupun berpapasan. Permukaan jalur pedestrian sudah menggunakan keramik kasar dan sudah dilengkapi dengan jalur untuk penyandang tuna netra namun belum ada jalur bagi penyandang tuna netra yang mengarahkan masuk ke dalam taman.

- Jalur masuk berupa ramp untuk penyandang disabilitas juga sudah tersedia di taman ini

- Jalur pedestrian sudah dilengkapi dengan pepohonan dengan peneduhan yang cukup.

- Penempatan zebra-cross hanya di dua sisi sehingga belum sesuai dengan kaidah keterhubungan. Namun demikian jalur masuk ke dalam taman hendaknya berdekatan dengan zebra-cross, sebab jika ธิ letaknya berjauhan, orang akan cenderung membuat jalan pintas sendiri yang dapat merusak tanaman.

- Penempatan bollard hanya di area masuk parkir motor, namun jarak antar bollard terlalu rapat sehingga agak menyulitkan pengendara motor.

- Jalur pedestrian, jalur masuk, dan sirkulasi internal taman sudah bebas dari gangguan baik berupa pot tanaman maupun ranting pepohonan. Selain itu jalur pedestrian juga sudah tersedia di sekeliling taman.

- Jalur pedestrian dan jalur sirkulasi taman sudah memiliki street furniture yang mendukung pengunjung taman seperti tempat duduk, tempat sampah, lampu taman, namun belum ada bollard di sekeliling taman untuk pengaman pejalan kaki. 


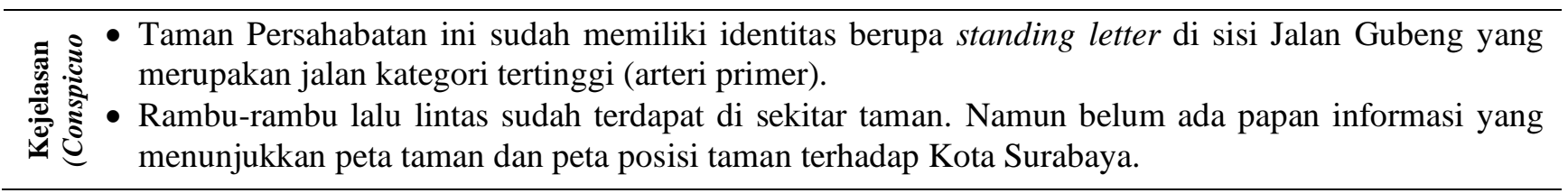

\section{Sumber: Analisa Penulis, 2020}

Carr (1992) menekankan bahwa ruang publik harus mampu memberikan arti. Begitu juga dengan taman kota yang merupakan sub-sistem dari ruang publik. Oleh karena itu arahan yang dapat diaplikasikan adalah dengan menambah value taman kota sebagai ruang informasi bagi pengunjung, baik yang berasal dari Surabaya maupun dari luar Surabaya. Selain itu Herbes (2010) juga memaparkan bahwa ruang publik seperti taman kota dapat dimanfaatkan untuk menempatkan informasi wayfinding berupa peta sekitar dengan radius yang masih terjangkau oleh pejalan kaki. Aplikasinya adalah dengan menempatkan papan informasi yang berisi peta Kota Surabaya, jalurjalur angkutan umum, serta informasi terbaru lain tentang Kota Surabaya.

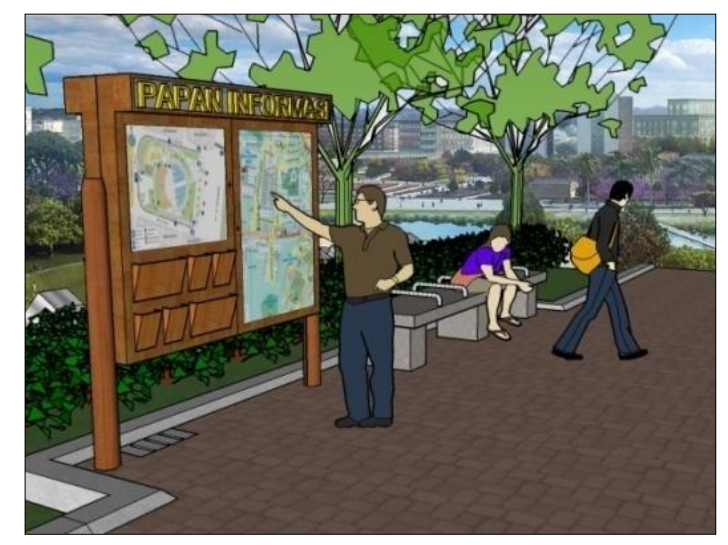

Gambar 9. Papan Informasi Pada Taman Kota Sumber: Dokumentasi Pribadi, 2020

\section{KESIMPULAN}

Berdasarkan observasi dan penilaian 5C's Walkability Audit pada taman kota dapat disimpulkan bahwa hampir seluruh variabel telah terpenuhi. Namun demikian perlu adanya upaya dan arahan yang lebih detail untuk memaksimalkan potensi taman kota dengan peningkatan walkability-nya, antara lain (1) Jalur penyeberangan hendaknya diletakkan di setiap sisi dari taman untuk meningkatkan keterhubungan antara ruang taman dengan ruang-ruang di sekitarnya; (2) Jalur penyeberangan hendaknya sebidang, bisa dengan menaikkan muka jalan, atau menurunkan trotoar dengan tambahan pengaman berupa bollard; (3) Letak jalur masuk taman sebaiknya tidak jauh dari penempatan jalur penyeberang jalan; (4) Taman kota dapat diintegrasikan sebagai ruang tempat informasi publik berupa peta yang menunjukkan posisi taman terhadap kota Surabaya.

Penelitian ini dapat dilanjutkan dengan studi penataan jalur sirkulasi pada ruang-ruang publik lain dengan pendekatan variabel yang sama. Studi tentang walkability ini dapat diintegrasikan dengan bidang-bidang lain seperti studi tentang transportasi umum maupun pengembangan wilayah yang berbasis TOD (Transit Oriented Development) yang saat ini sedang banyak dikembangkan di kota-kota di dunia. 


\section{Daftar Pustaka}

Asin, G. D. (n.d.). environment. (March 2008).

Budihardjo, E et al. (1998). Kota yang Berkelanjutan, Jakarta : Ditjen Dikti.

Carr, S et al. (1992). Public Space. USA: Cambridge University Press.

Darjosanjoto, E. (2006), Penelitian Arsitektur di Bidang Perumahan dan Permukiman. Surabaya: ITS Press.

Grant, J (2010). Bunbury CBD Walkability and Wayfinding Strategy. SWDC \& The City Of Bunbury

Herbes, B. (2010). Bunbury CBD Walkability. (March), 139.

Institute for Transportation and Development Policy (2018). Pedestrians First, Tools For a Walkable City. 1st ed. New York: ITDP.

Leather, J et al. (2011). Walkability and Pedestrian Facilities in Asian Cities. Manila, Philippines: ADB

Moura, F, P \& Gonçalves, A. B. (2017). Measuring walkability for distinct pedestrian groups with a participatory assessment method: A case study in Lisbon. Landscape and Urban Planning, 157(May 2018), 282-296. https://doi.org/10.1016/j.landurbplan.2016.07.002

Mayor of London. (2005). Transport for London Improving walkability. London

Ministry for The Environment. (2006). Urban Design Toolkit. Wellington, New Zealand
Pemerintah Indonesia. (2008). Peraturan Menteri Pekerjaan Umum Nomor 05/PRT/M/2008 tentang Pedoman Penyediaan dan Pemanfaatan Ruang Terbuka Hijau Di Kawasan Perkotaan. Indonesia

Pemerintah Indonesia. (2014). Peraturan Menteri Pekerjaan Umum Nomor 03/PRT/M/2014 tentang Pedoman Perencanaan, Penyediaan, dan Pemanfaatan Prasarana dan Sarana Jaringan Pejalan Kaki di Kawasan Perkotaan. Indonesia

Pemerintah Kota Surabaya. (2015). Rencana Pembangunan Jangka Menengah Daerah Kota Surabaya RPJMD tahun 2016-2020. Kota Surabaya

Ramayana. (2017). City And Its Open Spaces. International Journal of Scientific \& Technology Research, 6(2), 33-39.

Rice, L. (2008). Urban design Toolkit. In Urban Design International (Vol. 49). Retrieved from http://eprints.uwe.ac.uk/12781/

The Genesee Transportation Council. (2016). Walkability Action Plan. New York

Zahnd, M. (2006). Perancangan Kota secara Terpadu: Teori Perancangan Kota dan Penerapannya. Yogyakarta: Penerbit Kanisius. 